\title{
Geriatrik bireylerde düşme riskinin değerlendirilmesi ${ }^{1}$
}

\section{Dilek DORUK KONDAKCIa2 \& Aslı KILAVUZ ${ }^{\mathrm{b}}$}

aTrakya Üniversitesi, Keșan Hakkı Yörük Sağlık Yüksekokulu, Acil Yardım ve Afet Yönetimi Bölümü, Keșan - Edirne / Türkiye ORCID No: https://orcid.org/0000-0001-9752-3833

bEge Üniversitesi, Tıp Fakültesi, İç Hastalıkları AD, Bornova - İzmir / Türkiye

ORCID No: https://orcid.org/0000-0002-0474-9911

\begin{abstract}
ÖZET
Düssmeler yaşlılarda sık karşılaş̧ılan önemli geriatrik sorunlar arasında yer almaktadır. Düşme, bireyin bulunduğu yerden, dengesini yitirerek yukardan aşağıa inmesi olarak tanımlanmaktadır. Yaşlı bireylerde kapsamlı geriatrik değerlendirme yapılması büyük önem taşımaktadır. Sağllk personellerinde yaşlı bireylerin maruz kaldı ğı düșmelerin yaşlılığa bağlı gerçekleșen bir durum olmadığı konusunda farkındalık geliştirilmelidir. Yaşlılarda düssme risk faktörleri; ileri yaș, bilişssel ve duyusal bozukluklar, alt ekstremitelerde güç kaybı, yürüme ve denge sorunları, düsme öyküsü, çoklu ilaç kullanımı ve çevresel etkenlerin değerlendirilmesi önem taşıyan durumlardır. Düssme riskleri değerlendirilirken farklı ölçekler kullanılmaktadır. Düssmelerin önlenmesine yönelik koruyucu önlemlerin alınması büyük önem taşımaktadır. Bu derlemenin amacı yaşlılarda düssmelerin önlenebilmesi için risk faktörlerine ve bunların değerlendirilmesine vurgu yapmaktır.
\end{abstract}

\section{Evaluation of fall risk in the elderly}

\section{ABSTRACT}

Falls are among the most important geriatric problems encountered in the elderly. Fall; It is defined as where the individual loses his balance and goes from top to bottom. Comprehensive geriatric assessment is of great importance for older individuals. Awareness should be raised in health personnel that the falls to which elderly individuals are exposed are not a situation related to aging. Fall risk factors in the elderly; advanced age, cognitive and sensory disorders, loss of strength in the lower extremities, walking and balance problems, fall history, multiple drug use and environmental factors are important conditions. Different scales are used when evaluating the fall risks. It is of great importance to take protective measures to prevent falls. In this article, the evaluation of the fall risks of elderly individuals in the group with high fall risk and the tools used in the evaluation are discussed. The purpose of this review is to emphasize the risk factors and their evaluation in order to prevent falls in the elderly.

\section{MAKALE GEÇMIŞSI}

Geliş 17 Nisan 2020

Kabul 29 Haziran 2020

\section{ANAHTAR KELIMELER}

Yaşlı, düşme, düşme riski

\section{ARTICLE HISTORY}

Received 17 April 2020

Accepted 29 June 2020

\section{KEYWORDS}

Elderly, fall, fall risk

\section{GİRIS}

Dünyada yaşam beklentisinin artması ile birlikte yaşlı nüfusu artan toplumlar oluşmaya başlamıștır (OforiAsenso, Chin, Mazidi, Zomer, Ilomaki, Zullo, Gasevic, vd., 2019). Yaşlanan toplumlarda; kronik hastalıklarda artış, fonksiyonel bağımlılık, düşme korkusu, yaşam kalitesinde azalma, başkalarına bağımlılık ve erken ölümler gibi sonuçlardan dolayı düşmeler önemli bir halk sağlığı sorunudur (Perell, Nelson, Goldman, Luther, Prieto-Lewis, \& Rubenstein, 2001; Hausdorff, Rios \& Edelberg, 2001; Rhyn \& Barwick, 2019; Rasche, Nitsch, Rentemeister, Coburn, Buecking, Blimel, Bollheimer, Pape \& Knobe 2019).

Düşmeler dünya çapında kazara veya kasıtsız yaralanmalara bağlı ölümlerde önde gelen nedenler arasında yer almaktadır (Vakili, Taghipour, Farkhani, Bahrami, Beygi \& Pirizadeh, 2019). Düşmeler yaşlı bireylerin sürekli karșlaştıkları en ciddi sorunlardan olup, 65 yaş ve üstü her üç yaşlıdan biri ve 85 yaş ve üstü yaşlıların yarısı yılda en az bir kez düşmektedir (Monagle, 2002; Rubenstein, Stevens \& Scott, 2008; Gale, Cooper \& Sayer, 2016). Dünya Sağlı Örgütü raporlarına göre, bir kazanın neden olduğu ölümlerin \%40'ının düşmelerden kaynaklandığı bildirilmektedir (Yoo, Kim, Yim \& Jeon, 2019). Yaşlılarda düşmeler birden fazla etiyolojiye sahiptir (Vakili vd, 2019). Düşme nedenlerinin belirlenen sebepleri; denge ve yürüme bozuklukları, polifarmasi, kırılganlık, bilișsel sorunlar, görme sorunları ve daha önce düşme öyküsüdür (Ambrose, Paul \& Hausdorff, 2013; Jin, 2018). Yaşlı bireylerde fiziksel işlevlerin yaşa bağlı

\footnotetext{
${ }^{1}$ Makalenin Kaynak Olarak Gösterimi: Doruk Kondakçı, D., \& Kılavuz, A. (2020). Geriatrik bireylerde düşme riskinin değerlendirilmesi. Yaşlı Sorunları Araștırma Dergisi (YSAD), 13(1),56-63.

2 Sorumlu Yazar e-mail: ddkondakci@gmail.com
} 
değişimler (kas gücü kaybı, esneklik ve direncin azalması) nedeniyle azalması düşme riskini arttırmaktadır (Yoo, Kim, Yim \& Jeon, 2019). Araștırmalar düșmeye bağlı birçok travma ve ölümün önlenebilir olduğunu göstermektedir (Stevens, 2013). Literatürde yaș bireylerde ölüme neden olan sorunlar arasında yer almakta ve yıllar içinde ileri yaş gruplarında düşmeye bağlı ölüm oranlarında artış görülmektedir (Burns \& Kakara, 2018).

Yaşlı sağlığını korumak için öncelikli konulardan biri düşmelerin önlenmesidir (Vakili vd., 2019). Yașlanan toplumlarda yaşlıların sağlığını korumak için etkin yürütülen halk sağlığı programları gereklidir (Carlson, York \& Primomo, 2011). Önleyici programların geliștirilmesi için yaşlılarda tekrarlayan düşmelere neden olan faktörler belirlenmelidir (Yoo, Kim, Yim \& Jeon, 2019).

$\mathrm{Bu}$ derlemenin amacı yaşlılarda görülen geriatrik sendromlardan biri olan düșmelerin önlenebilmesi için düşme ile ilişkili risk faktörlerine ve bunların değerlendirilmesine vurgu yapmaktır.

\section{YAŞLILARDA DÜŞMELERIN EPIDEMIYOLOJISİ}

Dünya Sağlık Örgütü'nün 2015 yılı raporuna göre; 65 yaş ve üstü yaşlıların \%30'u, 85 yaş ve üstü yaşlıların $\% 50$ 'si yılda en az bir kez düşme riski ile karşılaşmaktadır (WHO, 2015; Rhyn \& Barwick, 2019). Bakım kurumlarında kalanların yarısı yılda bir kez düşmektedir (Perell vd., 2001). Ülkemizde yapılan çalışmalar yaşlı bireylerde düşme sıklığının \%35,662,0 arasında olduğunu göstermiștir (Aktürk \& İster, 2019). Telatar ve ark. Türkiye'nin en yüksek yaşlı popülasyonuna sahip olan ili Sinop'ta yaptıkları çalışmada düşme riskini \%36,4 olarak bulmuşlardır (Telatar, Üner, Özcebe, Biçer \& Sarı, 2020). Ülkemizde yapılan bir çalışmada ise yaşlıların \%48,7'sinin daha önce düștüğü, \%53,9'unun birden fazla düștügüu, düșme sonucu \%31,8'inde kırıkların görüldüğü ve \%51,1'inin düşme korkusu yaşadığı bildirilmiștir (Usta Yeşilbalkan, Ö. \& Karadakovan, 2005). Başka bir çalıșmada altmıș beș ve üzeri yaș grubunda 6 aylık ev içi ve dışı düşme oranının \%4,9 olduğu saptanmıștır (Kaymak Karataş \& Maral, 2001). Kaya ve ark.'nın yapmıș olduğu prospektif bir çalışmada düşme insidansı \%33,9 olduğu ve yaşlların \%35'inin düşme korkusu yașadığı belirlenmiștir (Apaydın Kaya, Kırıml, Kalaça, Çifçili, Cöbek Ünalan \& Kalaça, 2012). Okuyan ve ark.'nın çalışmasında, huzurevinde yaşayan yaşlıların \%65,3'ü düșme korkusu yașadı̆̆ı, \%49,2'si son bir yll içinde düştüğünü, son bir yll içinde düşenlerin \%75,4'ü en az bir kez düştüğünü belirtilmiştir (Birimoğlu Okuyan \& Bilgili, 2018).

Dünya Sağlık Örgütü 2017 yılında düşmeyi; "plansız ve ani gerçekleşen, yere, zemine veya diğer alt seviyelere gelerek, fiziksel yaralanmaya neden olan durum" olarak tanımlamaktadır (Asiri, Alshahrani, Aseeri, Alam, Ataalla, Almohiza \& Abdulhamed, 2018; Rhyn \& Barwick, 2019; Aktürk \& İster, 2019). Düșme nedeniyle meydana gelen yaralanmalar yaşlılarda önemli bir ölüm nedenidir (Perell vd., 2001). Düșmeler, dünya genelinde trafik kazalarından sonra ölüme neden olan kazalar arasında yer almaktadır (Saftari \& Kwon, 2018). Altmıș beș yaș ve üstü bireylerde acil servise başvuru nedenleri arasında düşmeler önemli yer tutmaktadır (Barker, Cameron, Flicker, Arendts, Brand,
Etherton-Beer, Forbes, vd., 2019). Her yll 1,9 milyondan fazla yaşlı düşmeye bağlı yaralanmalar nedeniyle acil servislere başvuru yapmaktadır (Moncana, 2011). Dünya genelinde yașllların acil servislerde hizmet almaları sorun yaratmaktadır (Barker vd., 2019). Ülkemizde acil servise başvuran yașlı hastaların Tanrıkulu ve Sarı'nın çalışmasında \%58,3'ünün, Erdem ve Atay'ın çalışmasında \% 95,5'inin yüksek düșme risk grubunda olduğu saptanmıștır (Tanrıkulu \& Sarı, 2017; Erdem \& Atay, 2018). Güner ve ark. çalışmasında yaşlıların \%33-36 oranında düștüğü ve hastanede yatan yaşlıların \%50'sinin düşme riski olduğu bildirilmiştir (Güner \& Nural, 2017).

Düşen yaşlı bireylerin her on tanesinden birinde ciddi yaralanma (kalça kırığı, subdural hematom, ciddi yumuşak doku yaralanmaları, kafa yaralanmaları vb.) gelişmekte ve bireyin hastaneye yatışı gerekebilmektedir (Baig, Gholamhosseini \& Connolly, 2016; Rhyn \& Barwick, 2019). Gökçek ve ark.'nın çalışmasında; düşme sonrası hastaların \%21,6'sında femur kırı̆̆ meydana gelmiștir (Gökçek, Gökçek, Yılmaz, Kasım, Yılmaz \& Özkara, 2019). Koparan ve ark.'ları ile Kundakçı ve ark.'larının çalışmalarında yaşlı bireylerde düşme sonrası kırıkların ilk sırada yer aldığı saptanmıștır (Koparan, 2012; Kundakçl, Yılmaz \& Sönmez, 2018).

Düșmeye bağlı ölümler son yıllarda $\% 42$ artıș göstermiştir (Moncada, 2011). Yaşlı ölümlerinin \%2340'ı düşmelere bağlı olarak gerçekleşmektedir (WHO, 2015). Avustralya, Kanada ve Birleșik Krallıkta 60 yaș ve üstü bireylerin düşme nedeniyle hastaneye başvuru oranı, yılda 10,000 nüfus başına 1,6-3,0 arasındadır (Baig vd., 2016). Amerika Birleșik Devletleri (ABD)'nde 2001 yılında acil servislerde düşmeye bağlı 1,6 milyon, 2012 yılında 2,4 milyon kiși tedavi edilmiștir (Barker vd., 2019). Batı Avustralya ve Birleşik Krallıkta 60 yaş ve üstü grubun acil servis ziyaretleri ile sonuçlanan düşme yaralanma oranları yılda 10,000 nüfus için 5,58,9 olarak gerçekleşmektedir (Baig vd., 2016). Amerika Birleșik Devletleri'nde ise her 15 saniyede bir hasta düşme nedeniyle acil servise başvurmakta, her 30 dakikada bir yașlı düşme nedeniyle hayatını kaybetmektedir (Asiri vd., 2018). Ülkemizde Taymaz'ın çalışmasında (2011) acil servise ayaktan başvuran hastaların \%16,9'u, yatan hastalarında \%13,9'u düşmeye bağlı olarak gerçekleşmiștir (Taymaz, 2011).

Avustralya'da sağlık harcamalarının \%1,5'i düşmeler nedeniyle ortaya çıan sağlı sorunlarına harcanmaktadır (Nunan, Wilson, Henwood \& Parker, 2018). Hızla artan yaşlı nüfusla birlikte düşmelere bağlı harcamalarında artması beklenmekte ve ABD'de düşmelere bağlı harcama oranın 2030 yılında 5,7 milyon olacağı öngörülmektedir (Rhyn \& Barwick, 2019; Barker vd., 2019). Türkiye'de düşme nedeniyle yapılan sağlık harcamalarına yönelik sınırlı sayıda çalıșma mevcuttur. Ülkemizde yapılan bir çalıșmada düşme nedeniyle hastaneye başvuran bir kişinin ortalama tedavi maliyeti (2016) $1.197,86 \pm 4.318,06 \mathrm{TL}$ olarak bildirilmiştir (Yağcl Şentürk, 2020).

\section{YAŞLILARDA DÜŞMELERINN DEĞERLENDİRILMESI}

Düşme ile meydana gelen fiziksel yaralanmalar yanında psikolojik ve sosyal sorunlarda ortaya çıkmaktadır. Düşme korkusu ve düşme sonrası kaygı sendromu en sık karşılaşılan sorunlardır (Baig vd., 
2016). Düşmeler yaşlı popülasyonunda yaygın olarak görülmesi ve yaralanmalara neden olmasına rağmen yaşlanma sürecinin bir parçası olarak görülmemelidir (Moncada, 2011). Yaşlı popülasyonda bireylerin düșme risklerinin tespit edilmesi zordur, düșmenin yaș ilerledikçe kaçınılmaz olması ve düşmenin normal bir durum olarak alglanması durumun önemsenmemesine neden olabilmektedir (Pape, Schemmann, Foerster \& Knobe, 2015; Rhyn \& Barwick, 2019; Rasche vd., 2019).

Amerikan Geriatri Derneği, 65 yaş ve üstü bireylerin yıllık düşme sayısı, düşme riski ve denge bozukluğu açısından değerlendirilmesi gerektiğini ileri sürmektedir (Moncada, 2011). Düşmeler, düşmeye bağlı yaralanma ve ölümler; düşmeye neden olan risklerin uygun araçlarla değerlendirilmesi ile önlenebilir (Moncada, 2011; Asiri vd., 2018). Düşmelerin çoğu çoklu risk faktörlerinin etkileşiminden kaynaklanmaktadır (Clemson, Mackenzie, Roberts, Poulos, Tan, Lovarini, Sherrington vd., 2018). Literatürde düşmeler ile risk faktörleri arasında pozitif ilişki olduğu görülmektedir (Pape vd., 2015).

Düşmeler; bireye ve çevreye bağlı risk faktörlerinden kaynaklanmaktadır (Barker vd., 2019; Aktürk \& İster, 2019).

\section{Düşme riskini arttıran bireysel (değiştirilemeyen risk)} faktörler:

- İlerlemiş yaș (80 yaş üzerinde olmak),

- Cinsiyet (Kadın olmak),

- Baş dönmesi,

- Nörolojik rahatsızlıklar (Parkinson, demans),

- Kronik hastalıklar (diyabet, artrit, inme),

- Kas gücünün azalması,

- Yürüme ve denge sorunları (örn: Yürürken veya kaldırıma çıkarken kararsızlık),

- Son bir ay içinde hastaneden taburcu olma

- Bireyin kullandığı ilaçlar (bireyin kullandığı ilaçların 4 ve üstünde olması),

- Yalnız yaşam,

- Düșme öyküsü,

- Düssme korkusu,

- Azalmış motor beceriler,

- Ortostatik hipotansiyon,

- Yardımcı araçların yanlıș kullanımı (Baston, Yürüteç vb)

- İssitme ve görme bozukluğu, lens kullanımıdır (Moncada, 2011; Pape vd., 2015; Clemson vd., 2018, Aktürk \& İster, 2019).

\section{Çevresel risk faktörleri}

- Islak zemin

- Banyo ve tuvalette tutunacak yerlerin olmamasl,

- Zeminde ve çevresindeki sabitlenmemiş nesnelerin varlığı,

- Kapı eșiği,

- Yetersiz aydınlatma,

- Uygun olmayan ayakkabıların kullanılmasıdır (Clemson vd., 2018; Aktürk \& İster, 2019).

Bazı çalışmalar risk faktörlerinin sayısı arttıkça buna paralel olarak düşme riskinin de önemli oranda arttığını göstermektedir (Baig vd., 2016; Clemson vd., 2018). Düșme riskinin erken tanımlanması düşmelerin öngörülmesi açısından önem arz etmektedir (Baig vd., 2016). Düşmeleri önlemek için kanıta dayalı yöntemlerin kullanılması önemlidir (Moncada, 2011). Literatüre göre yaşlılara uygun ve zamanında müdahale ile düşmelerin önlenebileceğine dair güçlü kanıtlar bulunmaktadır (Rhyn \& Barwick, 2019). Bu nedenle düşme riski erken yaşta (50 yaş ve üstü) tanımlanmalı ve bireyler izlenmelidir (Rasche vd., 2017).

Yaș; düșme nedenleri arasında yer alan önemli bir faktördür. İlerleyen yaşla birlikte düșme sayısında ve sıklığında artış görülmektedir (Aktürk \& İster, 2019). Yetmiş beș yaș ve üstü bireylerin \%70'i kazara düşmeye bağlı olarak hayatını kaybetmektedir (Ghahramani, 2016).

Düșük vücut ağırlığı, yürüme ve denge sorunları, görme bozukluğu ve psikoaktif ilaç kullanımı gibi risk faktörleri değiștirilerek düşme riski azaltılabilir (Baig vd., 2016). Yürüme ve denge sorunlarının egzersiz, denge, kuvvet ve yürüyüş eğitimleri ile düşme riskini azaltılabileceğine ilișkin A düzeyi kanıtlar bulunmaktadır. Düşme risk grubu içinde bulunan yaşlıların çok yönlü risk değerlendirilmesi yapılmalı ve gereksinimleri doğrultusunda uygun müdahaleler gerçekleștirilmesi A kanıt düzeyindedir (Moncada, 2011).

Literatürde düşme risklerini öngören ve yaşlı popülasyonda düşme olasılığını değerlendiren bazı değerlendirme araçları vardır (Asiri vd., 2018). Vlaeyen ve ark. video tabanlı ev analizi yaparak yeni bilgiler elde etmișlerdir (Vlaeyen, Deschodt, Debard, Dejager, Boonen, Goedeme, Vanrumste \& Milisen, 2013). Evde bakım profesyonellerine evde bakım alan yașlıların düșme riskini değerlendirmek için kanıta dayalı bir yöntem olan MAHC-10 bu değerlendirmelerden biridir (Asiri vd., 2018).

\section{Daha önceki düşmenin değerlendirilmesi}

Bireyin daha önce düșme öyküsünün varlığı gelecekte meydana gelebilecek düşmelerin belirlenmesinde önem taşımaktadır (Yılmaz Demir, 2011). Bireyin daha önce kaç kez düştüğü, tekrarlayan ve nedeni açıklanamayan düşmelerinin olup olmadığı, düşmeye bağlı herhangi bir semptom varlığı, yardımcı araç kullanımı, düștükten sonra yürüme ve denge sorunları ile ilgili bilgiler düşmeyi önleme ve yönetim için önemli göstergelerdir (Phelan, Mahoney, Voit \& Stevens, 2015; Moncada \& Mire, 2017). Bireyin düşme öyküsünün varlığı gelecekteki düșme riskini 1,27 oranında arttırmaktadır (Usta Yeşilbalkan \& Üstündağ, 2019).

\section{İlaç öyküsünün değerlendirilmesi}

Düşmelerde ilaç kullanım durumu üzerinde önemle durulması gereken ve en önlenebilir ancak en değişken konulardan biridir (Naharcı \& Doruk, 2009; Phelan vd., 2019). Bazı ilaçların kullanımı düşme riskini arttırmaktadır (Phelan vd., 2015). Bu nedenle hastalar ve bakım verenler çoklu ilaç kullanımı ve düșme riskini arttıran ilaçlar (benzodiazepinler, opioidler ve uyku ilaçları) konusunda eğitilmelidir (Moncada \& Mire, 2017; Abit Kocaman, 2019; Yllmaz \& Khorshid, 2019). 
İlaçlara ait kanıtlarda; psikotrop ilaçların doktor tarafından azaltılması ile düşmelerin \%66 oranında azaldığı, düşmeye neden olabilecek ilaçların azaltılması ile \%52 oranında azaldığı bildirilmiștir (Clemson vd., 2018). İlaçların (psikotrop veya diğer) azaltılması veya sonlandırılmasının düşme riski üzerindeki etkisi B düzeyi kanıttır (Moncada, 2011).

\section{Ortostatik Hipotansiyon}

Ortostatik hipotansiyon yaşlıların yaklaşık \%30'unu etkilemektedir. Ortostatik hipotansiyonu olan birey yürümede güçlük çeker ve düşmeye eğilimlidir (Phelan, Mahoney, Voit \& Stevens 2015).

\section{Denge ve yürümenin değerlendirilmesi}

Denge; ağırlık merkezini destek tabanı üzerinde tutarak düşmeyi önlemeye yardımcı olmaktadır (Ghahramani, 2016). Çalışmalar basit denge testinin düşme riskini belli düzeyde değerlendirebildiğini göstermektedir (Rasche vd., 2017). Bozulmuş denge ve yürüyüş düşme için en güçlü risk faktörüdür. Yaşlı bireylerde yaşa bağlı meydana gelen değişimlerin etkilendiği; motor refleksler, kas kuvveti ve tonüsü, adım uzunluğunun azalması gibi etkenlerle yürüme şekli değişmektedir (Yılmaz \& Khorshid, 2019).

\section{Çevredeki tehlikelerin değerlendirilmesi}

Çevresel değerlendirme, evdeki yürüme alanları veya merdivenlerdeki engelleri tehlikeyi ortadan kaldıracak şekilde gerekli düzenleme yapılmalıdır. Yaşlı için en riskli alanlar mobilyalar ve kaldırımlardır. Düşmenin en fazla görüldüğü alan ise ıslak zemin ve kaymaya bağlı gerçekleşen banyodur (Yılmaz \& Khorshid, 2019).

Yaşlılarda periyodik göz muayeneleri oldukça önemlidir. Gözde meydana gelen değişimler; görme keskinliği, alanını ve derinlik algısını etkilemektedir. Katarakt cerrahisi ile görme yetisinde iyileșme sağlanabilir (Naharcı \& Doruk, 2009; Yllmaz \& Khorshid, 2019; Abit Kocaman, 2019). Literatürde görmeye yönelik olarak riskin azaltılmasında katarak ameliyatı ile düşmelerin \%34 azaldığı görülmektedir (Clemson vd., 2018).

D vitamini eksikliği tanılanmış olan tüm yaşlıların, günde en az 800 IU D vitamini desteği almaları gerekmektedir (Kanıt A) (Moncada, 2011).

Genel olarak bilişsel bozulma, kronik hastalıklar ve fonksiyonel güç kaybı da düşmeye neden olmaktadır (Perell vd., 2001). Stevens ve ark. tarafından belirtildiği gibi Parkinson hastalığı, deliryum, felç ve artrit gibi bazı kronik hastalıkların semptomlarını belirlemek ve tedavi etmek düşme riskini azaltabilir (Baig vd., 2016). Ayrıca bilişsel bozuklukların düşmeleri üç kat arttırdığına yönelik kanıtlar da bulunmaktadır (Clemson vd., 2018).

Düşmeler yaşlı bireyin yaşam kalitesini, günlük yaşam aktivitelerini bağımsız olarak gerçekleştirme yani bireyin fonksiyonelliği son derecede önem taşıyan faktörlerdendir (Ghahramani, 2016; Asiri vd., 2018). Düşme sıklığı ile günlük yaşam aktivitelerini bağımsız gerçekleştirme arasında ilişki olduğu savunulmaktadır. Yürümeye yardımcl araç kullanan yaşlılar daha sık düşmektedir (Aktürk \& İster, 2019).

Düșmelerin etkileri ve düșmeye müdahalelerin maliyetinin yüksek olması, düșme riski yüksek olan kişilerin belirlenmesinin önemini ortaya koymaktadır (Hausdorff, Rios \& Edelberg, 2001). Amerika Birleşik Devletleri, İngiltere ve Almanya yaşlılarda düșme riskinin rutin olarak değerlendirildiği ülkelerdir (Perell vd., 2001).

Düșme riskini araștıran çalıșmalar genellikle sağlık kuruluşlarında (örneğin; hastaneler ve bakım evleri vb.) yapılmaktadır (Pape vd., 2015). Dünya Sağllk Örgütü tarafından da yaşlı bakım kurumlarında 65 yaș üstü bireylerin $\% 50$ 'den fazlasının düştüğü belirtilmektedir (WHO, 2018). Bu durum diğer literatür bilgileri ile uyum göstermektedir (Nunan, Wilson, Henwood \& Parker, 2018).

Yaşlı bireyler ev dişında pek çok riskle karşı karşıya kalmaktadır (Pape vd., 2015). Asiri ve ark.'nın çalışmasında düşmelerin \% 56'sının sokakta veya halka açık bir yerde olduğu yani ev dişında gerçekleştiği bildirilmektedir. Ev içinde meydana gelen düșmeler ise genellikle yatak odası veya yemek odasında gerçekleşmektedir (Asiri vd., 2018). Ev güvenliğinin sağlanması ile düşmelerin $\% 41$ oranında azaltılabileceğine yönelik kanıtlar bulunmaktadır (Clemson vd., 2018).

Hastanede kalış süreci içinde meydana gelen düşmeler dünya çapında sorun olușturmakta olan en yaygın karşılașllan durumlardan biridir (Baig vd., 2016; Said, Churilo \& Shaw, 2017). Avusturalya hastanelerindeki akreditasyon standartlarından biri de düșmelerden kaynaklanan zararların önlenmesidir (Said vd., 2017). Hastane düşmeleri hasta güvenliği olaylarında Birleşik Krallık'ta \%41, Avustruralya'da \%38 yer tutmaktadır (Hemsley vd., 2019). Hastane ortamında meydana gelen düșme sonrası bireyin hastanede kalıș süresi 812 gün uzamakta ve bakım maliyetinin $\% 61,4$ artacağ öngörülmektedir (Kafantogia, Katsafourou, Tassiou \& Nikoletta, 2017; Hemsley vd., 2019).

Uzun dönem bakım evleri, yaşlı bireylerin daha sık düştügü yerler olup daha fazla risk oluşturduğundan öncelikli alanlar kabul edilmelidir (Nunan vd., 2018). Bir kez düşmüş olan yaşlı bireyler daha fazla düşme riski altındadır ve \%52'si düșme sonrasındaki 12 ay içinde tekrar düşmektedir (Ghahramani, 2016). Yaşlıların ikincil düşmesini önlemeye yönelik çok az kanıt bulunmaktadır (Barker vd., 2019).

Günümüzde düşme riski değerlendirme algoritmaları hastane ortamında ve sağlık profesyonelleri tarafından uygulanmaktadır (Rasche vd., 2017). Klinik uygulamalarda sürdürülebilir düşmeyi önleme yollarının oluşturulması aciliyet gerektiren konular arasında yer almaktadır (Rhyn \& Barwick, 2019). Düșme riski değerlendirme araçlarının kullanımı düşmelerin önlenmesine, düşmeye yönelik stratejilerin belirlenmesine ve düșmelerin azaltılmasına yardımcı olacaktır (Nunan vd., 2018).

Hastanede meydana gelen düşmelerin önlenmesinde ve risklerin değerlendirilmesinde kullanılan ölçekler; Downton Düşme Riski Değerlendirme Ölçeği, Thomas Risk Değerlendirme Ölçeği (STRATIFY) ve Morse Düșme Ölçeği'dir (Hemsley vd., 2019). Ülkemizde kullanılan düșme ölçekleri; İtaki düşme ölçeği, Harizmi düşme ölçeği, Morse Düşme Ölçeği ve Hendrich II Düşme Ölçeği'dir (Ürkmez, Özel, Sertoğlu, Çevik, Koç, Demirey \& Cebeci, 2015).

Hendrich II Düşme Risk Ölçeği; 1995 yllında 
geliştirilmiş ve 2005 yılında revize edilmiştir (Özden, Karagözoğlu \& Kurukız, 2012). Ölçek yedi faktör içermektedir. Bu faktörler konfüzyon/dezoryantasyon, depresyon, emilimde değișim, baș dönmesi, cinsiyet, antiepileptik/benzodiyazepin kullanımı ve kalkma yürüme testidir. Ölçekte beş ve üzeri puan alan ve son üç ayda düşmüş hastalar yüksek riskli olarak değerlendirilmektedir (Yılmaz Demir, 2011).

STRATIFY (St Thomas Risk Değerlendirme Aracı), yatarak tedavi gören düşme için risk taşıyan yaşlı hastalara kullanılmaktadır. $\mathrm{Bu}$ araçta yer alan faktörler; düşme hikayesinin bir şikayet biçiminde sunulması, mental durumda konfüzyon, dezoryantasyon ve ajitasyonun bulunması, görme bozukluğu, sık tuvalete gitme ihtiyacl, transfer ve yürüyüştür. Her madde bir puanla değerlendirilmektedir. Eğer hasta ölçekte üç ve üzeri puan alırsa düşmeler yönünden riskli değerlendirilmektedir (Yllmaz Demir, 2011).

FRAT (Düşme Riski Değerlendirme Aracı) ilk kez 1999 yılında Peninsula Sağlık Düşmeleri Önleme Merkezi tarafından oluşturulmuştur. Ölçeğin revize olan son hali üç bölümden oluşmaktadır. Her probleme yönelik riski en aza indirmek için stratejiler belirlenir ve ek stratejilere gereksinim olup olmadığı yönünde değerlendirme gerçekleştirilir (Yılmaz Demir 2011).

Morse Düssme Ölçeği 1987 yılında Janica Morse tarafından yaşlılardaki düşme riski tanılama aracı olarak geliştirilmiştir (Özden vd., 2012). Ölçek; düşme hikayesinin varlığı, ikincil tanı, mobilizasyon desteği, intravenöz yol varlığı ya da heparin kullanımı, yürüyüş/transfer ve mental duruma yönelik değerlendirmeleri içermektedir (Yllmaz Demir 2011).

Ittaki Düșme Riski Ölçeği; 17 yaș ve üzerindeki hastalar için oluşturulmuş olan ölçek, hasta demografik bilgilerini, değerlendirme yapma nedenini, major ve minör risk faktörlerini içermektedir. Ölçekte toplam 19 madde mevcuttur. Ölçek skoru tüm maddelerin aldığı puanlar toplanarak oluşturulur. Toplam skor 0-4 Puan arasında ise; Düşük Risk, 5 puan ve üzerinde ise yüksek risk kabul edilir (Tanıl, Çetinkaya, Sayer, Avșar \& İskit, 2014).

Harizmi Düssme Riski Ölçeği; 0-16 yaș arasında hastalar için oluşturulmuş olan ölçekte, hasta demografik bilgileri, değerlendirme yapma nedeni ve 9 madde bulunmaktadır. Ölçek skoru tüm maddelerin aldığı puanlar toplanarak olușturulur. Toplam skor 0-14 puan arasında ise; Düşük Risk, 15 puan ve üzerinde ise yüksek risk kabul edilir (Tanıl vd., 2014).

Yaşlılara yönelik düşme riski değerlendirme araçları, hasta özelliklerini ve düșmelere katkıda bulunan çevresel faktörler ve ilaç kullanım durumlarının değerlendirilmesine yönelik sonuçları yeterince yansıtmamaktadır (Yılmaz \& Khorshid, 2019).

Tablo 1. Yaşlılarda düşme riskini azaltacak müdahaleler

\begin{tabular}{ll}
\hline \multicolumn{1}{c}{ RISKK FAKTÖRLERİ } & \multicolumn{1}{c}{ MÜDAHALELER } \\
\hline $\begin{array}{l}\text { Postural hipotansiyon: Ayakta dururken sistolik kan } \\
\text { basıncında } \geq 20 \mathrm{~mm} \text { Hg düşme veya sistolik kan }\end{array}$ & Yatak başının kaldırılması gibi önlemler \\
basıncının $<90 \mathrm{~mm}$ Hg olması & $\begin{array}{l}\text { Hipotansiyona katkıda bulunabilecek bir ilacın dozunu } \\
\text { azaltma; gerekirse, kesilmesi veya başka bir ilaç ile } \\
\text { değiştirilmesi }\end{array}$ \\
& Basınç çorapları \\
& Endike ise, kan basıncını arttırmak için fludrocortisone \\
& kullanılması (günde iki veya üç kez 0.1 mg) \\
Bir benzodiazepin veya diğer sedatif-hipnotik bir ilacın & Sedatif-hipnotik ilaçların kullanımı hakkında eğitim \\
kullanımı & Uyku sınırlaması gibi uyku problemlerinin farmakolojik \\
& olmayan tedavisi \\
İlaçların azaltılması ve kesilmesi \\
Dört veya daha fazla reçeteli ilaç kullanımı & İlaçların gözden geçirilmesi \\
Düşmeye yol açan çevresel tehlikeler & Daha güvenli mobilyaların seçimi (doğru yükseklikte, \\
& daha stabil) ve banyolarda tutma çubukları veya \\
merdivenlerde tırabzan gibi yapların montajı gibi
\end{tabular}

Kaynak: Tinetti, M. E., Baker, D. I., McAyay, G., Claus, E. B., Garrett, P., Gottschalk, M., Koch, M. L., Trainor, K. \& Horwitz, R. I. (1994). A multifactorial intervention to reduce the risk of falling among elderly people living in the community. $N$ Engl J Med, 331, 821-7. 


\section{Düşmelerin önlenmesi}

Düşme sebebi belirlenemediğinde veya bir yaşlının düşme riski yüksek olduğunda, düşmeyi önlemek ve düşme oranını azaltmak için çevresel tehlikelerin azaltılması ve kan basıncının, görme problemlerinin ve depresyon dahil olmak üzere ruhsal durum değişikliklerinin değerlendirilmesi ve tedavisi gibi müdahaleler gerekmektedir. Düșmeleri azaltmada başarılı olabilecek müdahaleler Tablo 1'de listelenmiştir.

\section{SONUÇ VE ÖNERİLER}

Yaşlı bireylerde sık görülen geriatrik sendromlardan biri olan düşmeler önemli sağllk sorunları arasında yer almaktadır. Düşmeye sonucu ortaya çıkan travmaların tedavisi sırasında, genellikle düșme nedeni dikkate alınmamaktadır. Düşme nedeniyle sağlık kuruluşuna bașvuran yașlı bireyin düștüğünü ifade etmemesi, sağlık personelinin öykü alırken düşmeyi yaşlılığın olağan süreci olarak değerlendirmesi nedeniyle yeterli sorgulama gerçekleștirilmemektedir. Yaşlı bireylerde meydana gelen düşmeler ayrıntılı sorgulama ve kapsamlı geriatrik değerlendirmeyi gerektirmektedir. Bu nedenle tüm yașlllarda düșme ile ilișkili risk uygun ölçekler kullanılarak belirlenmeli ve düşmeleri önlemek için gerekli önlemler alınmalıdır. Bireyin durumunu etkileyen fiziksel, psikolojik ve çevresel faktörler tanımlanmalıdır. Tekrarlayan düșmelerin önlenmesi için çeşitli algoritmalar geliştirilmelidir.

\section{Çıkar Çatışması / Conflict of Interest}

Yazarlar tarafından herhangi bir çıkar çatışması beyan edilmemiştir / No conflict of interest was declared by the authors.

\section{KAYNAKÇA}

Abit Kocaman, A. (2019). Düssme Hikayesi Olan Yaşlı Bireylerde Farklı Tip Egzersiz Eğitimlerinin Fonksiyonellik Üzerine Etkisi. Hacettepe Üniversitesi Sağlık Bilimleri Enstitüsü, Fizik Tedavi ve Rehabilitasyon Programı Doktora Tezi. Ankara

Aktürk, Ü., \& İster, E. D. (2019). Some features of hospitalized elderly and effects of fall behavior on fall risk. Medicine Science, 8(3), 606-612.

Ambrose, A. F., Paul, G., \& Hausdorff, J. M. (2013). Risk factors for falls among older adults: A review of the literatüre. Maturitas, 75(1), 51-61.

Apaydın Kaya. Ç., Kırımlı, E., Kalaça, Ç., Çifçili, S., Cöbek Ünalan, P., \& Kalaça, S. (2012). Huzurevlerinde kalan yaşlılarda düşme insidansı ve düşme ile ilişkili faktörler. Türk Geriatri Dergisi, 15(1), 406. Available from: http://geriatri.dergisi.org/ pdf/pdf_TJG_624.

Asiri, F. Y., Alshahrani, A., Aseeri, M. F., Alam, M. M, Ataalla, S. M., Almohiza, M. A., \& Abdulhamed, I. A. (2018). Fall risks factors among home-based health care patients in the Aseer province: Observational study. Biomedical Research, 29(12), 2640-2645.

Baig, M. M., Gholamhosseini, H., \& Connolly, M. J.
(2016). Falls risk assessment for hospitalised older adults: a combination of motion data and vital signs. Aging Clin Exp Res, 28(6), 1159-1168.

Barker, A., Cameron, P., Flicker, L., Arendts, I. G., Brand, C., Etherton-Beer, I. C., Forbes, I. A., Haines, I. T., Hill, I. A. M., Hunter, P., Lowthian, J., Nyman, I. S. R., Redrern, I. J., Smit, D. V., Waldron, N., Boyle, E., Macdonald, E., Ayton, D., Morello, R., \& Hill, K. (2019). Evaluation of RESPOND, a patientcentred program to prevent falls in older people presenting to the emergency department with a fall: A randomised controlled trial. PLOS Medicine, 16(5), e1002807. doi:10.1371/journal.pmed.1002807

Birimoğlu Okuyan, C., \& Bilgili, N. (2018). Yaşlılarda mobilite ve düşme davranışları: Bir huzurevi çalışması. Hemşirelikte Eğitim ve Araștırma Dergisi, 15(1), 1-8. doi:10.5222/HEAD.2018.001

Burns, E., \& Kakara, R. (2018). Deaths from falls among persons aged $\geq 65$ years-United States, 20072016. Centers for Disease Control and Prevention Morbidity and Mortality Weekly Report, 67(18), 509-514.

Carlson, T., York, S., \& Primomo, J. (2011). The utilization of geographic information systems to create a site selection strategy to disseminate an older adult fall prevention program. The Social Science Journal, 48(1), 159-174. doi:10.1016/ j.soscij.2010.09.002

Clemson, L., Mackenzie, L., Roberts, C., Poulos, R., Tan, A., Lovarini, M., Sherrington, C., Simpson J.M., Willis K., Lam M., Tiedemann A., Pond D., Peiris D., Hilmer S., Pit S.W., Howard K., Lovitt L., White F. (2017). Integrated solutions for sustainable fall prevention in primary care, the iSOLVE project: a type 2 hybrid effectiveness-implementation design. Implementation Science, 12(1), 12. doi:10.1186/s13012-016-0529-9

Erdem, Ö., \& Atay, S. (2018). Acil servise başvuran bireylerde düşme riski ve etkileyen faktörlerin incelenmesi. Hacettepe Üniversitesi Hemşirelik Fakültesi Dergisi, 5(2), 128-137. doi:10.31125/ hunhemsire.454362

Gale, C. R., Cooper, C., \& Sayer, A. A. (2016). Prevalence and risk factors for falls in older men and women: The English longitudinal study of ageing. Age and Ageing, 45, 789-794. doi:10.1093/ageing/ afw129

Ghahramani, M. (2016). Fall risk assessment in older people. The International Journal of Engineering and Science (IJES), 5(11), 1-14.

Gökçek, M. B., Gökçek, İ., Yılmaz, T., Kasım, İ., Yılmaz, T. E., \& Özkara, A. (2019). Düşme şikayeti ile acil servis başvuran 65 yaș ve üzeri hastaların düşme nedenleri ve risk faktörlerinin araştırılması, Konuralp Tip Dergisi, 11(2), 217-226.

Hausdorff, J. M., Rios, D. A., \& Edelberg, H. K. (2001). Gait variability and fall risk in community-living older adults: A 1-Year prospective study. Arch Phys Med Rehabil, 82(8), 1050-1056.

Hemsley, B., Stee,l J., Worrall, L., Hill, S., Bryant, L., Johnston, L., Georgiou, A., \& Balandin, S. (2019). 
A systematic review of falls in hospital for patients with communication disability: Highlighting an invisible population. Journal of Safety Research, 68, 89-105.

Jin, J. (2018). US Preventive Services Task Force. Interventions to prevent falls in communitydwelling older adults. JAMA, 319(16), 16961704. doi:10.1001/jama.2018.3097

Kafantogia, K., Katsafourou, P., Tassiou, A., \& Vassou, N. (2017). Falls among hospitalized patients. Journal of Frailty, Sarcopenia and Falls, 2(3), 5357.

Kaymak Karataş, G., \& Maral, I. (2001). Ankara-Gölbașı ilçesinde geriatrik popülasyonda 6 aylık dönemde düşme sıklığı ve düşme için risk faktörleri. Turkish Journal of Geriatrics, 4(4), 152-158.

Koparan, S. (2012). 2000-2010 Yillart Arasinda Akdeniz Üniversitesi Hastanesine Düssme Nedeniyle Başvuran 65 Yaş ve Üzeri Hastaların Retrospektif Değerlendirilmesi. Akdeniz Üniversitesi Tipta Uzmanlık Tezi. Antalya.

Kundakçı, G. A., Yılmaz M., \& Sönmez, M. K. (2018). Yaşlılarda düşme ve düşmeye ilişkin özelliklerin incelenmesi. Ege Üniversitesi Hemșirelik Fakültesi Dergisi, 34(3), 73-88.

Monagle, S. (2002). Reducing falls in community dwelling elderly:the role of GP care planning. Reprinted from Australian Family Physician, 31(12), 1111-1115.

Moncada, L. V. V. (2011). Management of falls in older persons: A prescription for prevention. American Family Physician, 84(11), 1267-1276.

Moncada, L. V. V., \& Mire, L. G. (2017). Preventing falls in older persons. Am Fam Physician, 96(4), 240247.

Naharcl, M. İ. \& Doruk, H. (2009). Yașlı popülasyonda düşmeye yaklaşım. TAF Prev Med Bull, 8(5), 437444.

Nunan, S., Wilson, C. B., Henwood, T., \& Parker, D. (2018). Fall risk assessment tools for use among older adults in long-term care settings: A systematic review of the literatüre. Australasian Journal on Ageing, 37(1), 23-33.

Ofori-Asenso, R., Chin, K. L., Mazidi, M., Zomer, E., Ilomaki, J., Zullo, A. R., Gasevic, D., Ademi, Z., Korhonen, M. J., LoGiudice, D., Bell, J., \& Liew, D. (2019). Global incidence of frailty and prefrailty among community-dwelling older adults a systematic review and meta-analysis. JAMA Network Open, 2(8), e198398. doi:10.1001/ jamanetworkopen.2019.8398

Özden, D., Karagözoğlu, Ş., \& Kurukız, S. (2012). Hastaların iki ölçeğe göre düşme riskinin belirlenmesi ve bu ölçeklerin düşmeyi belirlemedeki duyarlılı̆̆ı: Pilot çalıșma. Anadolu Hemșirelik ve Sağlık Bilimleri Dergisi, 15(2), 8088.

Pape, H., Schemmann, U., Foerster, J., \& Knobe, M. (2015). The 'Aachen Falls Prevention Scale'development of a tool for self-assessment of elderly patients at risk for ground level falls.
Patient Safety in Surgery, 9(7), 1-6.

Perell, K. L., Nelson, A., Goldman, R. L., Luther, S. L., Prieto-Lewis, N., \& Rubenstein, L. Z. (2001). Fall risk assessment measures: An analytic review. Journal of Gerontology: Medical Sciences, 56(12), 761-766.

Phelan, E. A., Mahoney, J. E., Voit, J. C. \& Stevens, J. E. (2015). Assessment and management of fall risk in primary care settings. Med Clin North Am, 99(2), 281-293. doi:10.1016/j.mcna.2014.11. 004.

Rasche, P., Mertens, A., Brölhl, C., Theis, S., Seinsch, T., Wille, M., Pape, H., \& Knobe M. (2017). The "Aachen fall prevention App"-a Smartphone application app for the self-assessment of elderly patients at risk for ground level falls. Patient Safety in Surgery, 11, 14.

Rasche, P., Nitsch, V., Rentemeister, L., Coburn, M., Buecking, B., Blimel, C., Bollheimer, L.C., Pape, H., \& Knobe M. (2019). The Aachen Falls Prevention Scale:Multi-Study evaluation and comparison. JMIR Aging, 2(1), e12114. doi:10.2196/12114

Rhyn, B., \& Barwick, A. (2019). Health Practitioners' perceptions of falls and fall prevention in older people: A metasynthesis. Qualitative Health Research, 29(1), 69-79. doi: 10.1177/1049732318805753

Rubenstein, L. Z., Stevens, J. A., \& Scott, V. (2008). Interventions to prevent falls among older adults, Handbook of Injury and Violence Prevention. 3753.

Saftari, L. N., \& Kwon, O. (2018). Ageing vision and falls: A review. Journal of Physiological Anthropology, 37, 11. doi: 10.1186/s40101-018-0170-1

Said, C. M., Churilo, L., \& Shaw, K. (2017). Validation and inter-rater reliability of a three item falls risk screening tool. BMC Geriatrics, 17(1), 273. doi: 10.1186/s12877-017-0669-z

Stevens J. A. (2013). The STEADI Tool Kit: A fall prevention resource for health care providers. IHS Prim Care Provid. 39(9), 162-166.

Tanıl, V., Çetinkaya, Y., Sayer, V., Avșar, D., \& İskit, Y. (2014). Düşme riskinin değerlendirilmesi. Sağlık Akademisyenleri Dergisi, 1(1), 21-26.

Tanrıkulu, F., \& Sarı, D., (2017). Determining patients' risk of falling in the emergency department. International Journal of Caring Sciences, 10(2), 907-914.

Taymaz, T., (2011). Akademik Geriatri Kongresi, 2011. Kongre Bildiri Kitabl, 132-133. http://www. Akademikgeriatri.org/files/Akademik Geriatri 2011/geriatriKitap2011.pdf

Telatar, T. G., Üner, S., Özcebe, H., Biçer, B. K., \& Sarı, Ö. Y. (2020). Yaşlılarda düşmeler ve ilişkili risk faktörlerinin yaş ve cinsiyete göre değerlendirilmesi. Selcuk Med J, 36(2), 101-108.

Tinetti, M. E., Baker, D. I., McAyay, G., Claus, E. B., Garrett, P., Gottschalk, M., Koch, M. L., Trainor, K., \& Horwitz, R. I. (1994). A multifactorial intervention to reduce the risk of falling among elderly people living in the community. $N$ Engl J Med, 331, 821-827. 
Usta Yeșilbalkan, Ö., \& Karadakovan, A. (2005). Narlıdere Dinlenme ve Bakımevinde yaşayan yaşlı bireylerdeki düşme sıklığı ve düşmeyi etkileyen faktörler. Turkish Journal of Geriatrics, $8(2), 72-77$.

Usta Yeşilbalkan, Ö., \& Üstündağ, S. (2019). Kanserli bireylerde düşmeler. Hemşirelikte Eğitim ve Araştırma Dergisi,16(2),152-159.

Ürkmez, D. Ö., Özel, H. Ö., Sertoğlu, E., Çevik, L. Ç., Koç, S., Demirey, S., \& Cebeci, Z. (2015). Okmeydanı Eğitim ve Araştırma Hastanesinde çalıșan hemşirelerin hasta düşmelerine yönelik aldıkları önlemlerin değerlendirilmesi. Okmeydanı Tip Dergisi, 31(4), 184-188. doi:10.5222/otd.2015. 1016

Vakili, V., Taghipour, A., Farkhani, E. M., Bahrami, H. R., Beygi, B., \& Pirizadeh, E. (2019). Risk factors for falls among elderly people. Elderly Health Journal, 5(2), 84-91.

Vlaeyen, E., Deschodt, M., Debard, G., Dejager, E., Boonen, S., Goedeme, T., Vanrumste, B., \& Milisen, K. (2013). Fall incidents unraveled: A series of 26 video-based real-life fall events in three frail older persons. BMC Geriatr, 13, 103. doi:10.1186/ 1471-2318-13-103

World Health Organization, (2015). https://www. who.int/ageing/publications/world-report2015/en/ adresinden alındı.

Yağcı Şentürk, A. (2020). Yaşlılarda düșme oranları ve düşme önlemleri. Anadolu Güncel Tıp Dergisi, 2(2), 47-52. doi:10.38053/agtd.694931

Yllmaz, S., \& Khorshid, L. (2019). Yașlı hastalarda düşmeler ve risk faktörleri. İzmir Kâtip Çelebi Üniversitesi Sağlık Bilimleri Fakültesi Dergisi, 4(3), 117-121.

Yılmaz Demir, N. (2011). Morse Düssme Ölçeğinin Türkçe'ye Uyarlanması ve Duyarlılık Seçicilik Düzeyinin Belirlenmesi. Dokuz Eylül Üniversitesi Sağlık Bilimleri Enstitüsü, Hemşirelikte Yönetim Anabilim Dalı Yüksek Lisans Tezi. İzmir.

Yoo, J. S., Kim, C. G., Yim, J. F., \& Jeon, M. Y. (2019). Risk factors of repeated falls in the old people. Korean Society of Exercise Rehabilitation, 15(2), 275281. 